\title{
Intelligent power monitoring and control with wireless sensor network techniques
}

\author{
Iman Mohammed Nayyef, Anas Ali Hussien
}

Department of Computer Engineering, Al-Nahrain University, Iraq

\begin{tabular}{l}
\hline Article Info \\
\hline Article history: \\
Received Aug 18, 2019 \\
Revised Dec 19, 2019 \\
Accepted Dec 3, 2019
\end{tabular}

\section{Keywords:}

IoT

Power management

Smartphone app

WSN

Zigbee

\begin{abstract}
Undoubtedly, there is a necessity for establishing a more intelligent power system in the existing energy system, which is increased according to the development of wireless system network (WSN) and the Internet of Things (IoT). This study presents intelligent power monitoring and control with wireless sensor network techniques, based on WSNs and IoT technologies is designed to manage real-time power at buildings. This system includes a complete network of wireless sensing node, base station and a smart home gateway. A sensing node is utilized as wireless sensors to measure voltage and current and to calculate power consumption of connected appliances that are transmitted wirelessly to a base station via Zigbee node. A base station is designed to receive all data transmitted from the sensing node and display it through GUI available at the personal computer with the possibility of controlling ON and OFF appliances according to consumer requirements. All of these readings are stored at database for analysis. In addition, a smart home gateway is used to connect the system with internet, allowing consumers to continuous monitoring and remote control the appliances via a smartphone application. The benefit of this system is that the mechanism of appliances control can be done in different ways (manually, automatically and remotely). To ensure better accuracy of the equipment many appliances are tested and compared with practical measurement. Best results are obtained for the error, voltage, current and the power.
\end{abstract}

Copyright $\odot 2020$ Institute of Advanced Engineering and Science. All rights reserved.

\section{Corresponding Author:}

Anas Ali Hussien,

Department of Computer Engineering, Al-Nahrain University, Baghdad, Iraq. Email: anasali78@yahoo.com

\section{INTRODUCTION}

Recently, a great attention has been paid to wireless sensor networks (WSNs) because of their significant advantages. WSNs are extensively employed in weighing and observing application areas like Internet of things (IoT), smart grids, smart cities and homes, cloud computing, healthcare monitoring, military investigation and environmental surveillance systems [1-2]. It is a fact that there is an increasing demand for electricity with the decrease in the natural fuels owing to the high-energy use. Significant interruptions will be resulted throughout the world due to the gap between demand and supply and the reduction of automation and control equipment [3-4].

Intelligent Energy Networks consist of devices that can fulfill their functions in an energy-efficient way, having the capabilities of communication and remote control. Thus, devices like smart energy meters have witnessed attraction to be used to generate power and distribute industry which achieves the Smart Grids vision [5]. The convergence of computing, sensing and networking technologies has resulted in the Internet of Things (IoT). This allows intercommunication between devices of different sizes and computational capabilities (things). This is done locally through enabling what is called edge and fog computing or through the fixed internet infrastructure, utilizing the computational resources in the cloud. A 
new class of applications is enabled in several areas including energy management, healthcare and smart cities through the IoT paradigm, as illustrated in Figure 1 [6].

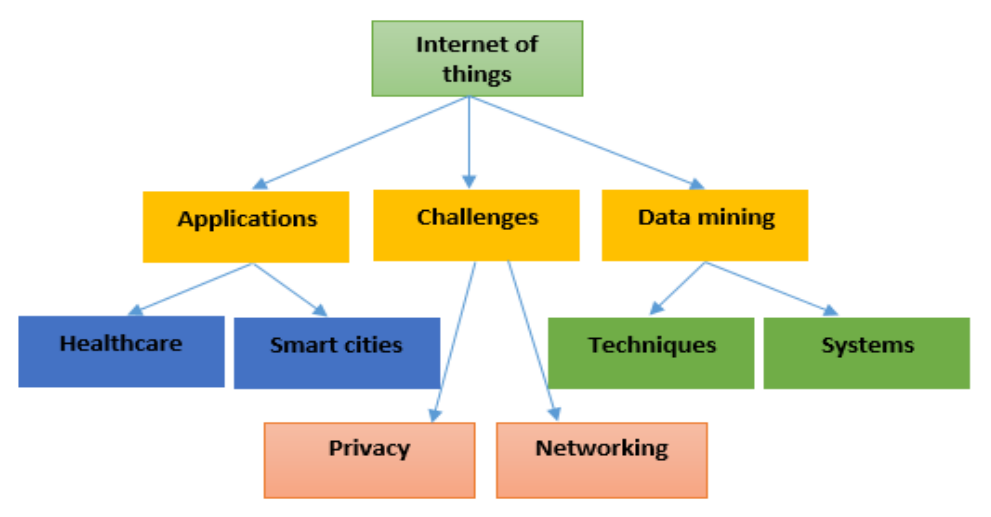

Figure 1. IOT applications

The next-generation wireless communication system has witnessed the improvement of a new phenomenon represented by integrating techniques of simultaneous wireless information and power transfer (SWIPT) and cooperative relay (CoR). The CoR technique is employed to obtain energy and spectral efficient network as well as solving the issues of shadowing, path loss, fading and smaller coverage area. Relay nodes are battery-constrained or battery-less devices [7].

The energy consumption is reduced by the means of industrial monitoring. In addition, WSNs has variety ways for the connections, power management support through the newest versions of the sensors and internet services and protocols for measuring, visualization, managing and control of physical variables such as pressure, current, voltage, power. These data have been sensed and transimitted vial wireless networks [8].

A WSAN performance is fabricated based on the IoT techniques to obtain better support to intelligent power monitoring system and consumption of energy. These performances an efficient way to develop the characteristics of the complete process control to optimize the system operation to reduce power consumption during the period of operation [9]. The system operation and architecture can be illustrated as in Figure 2.

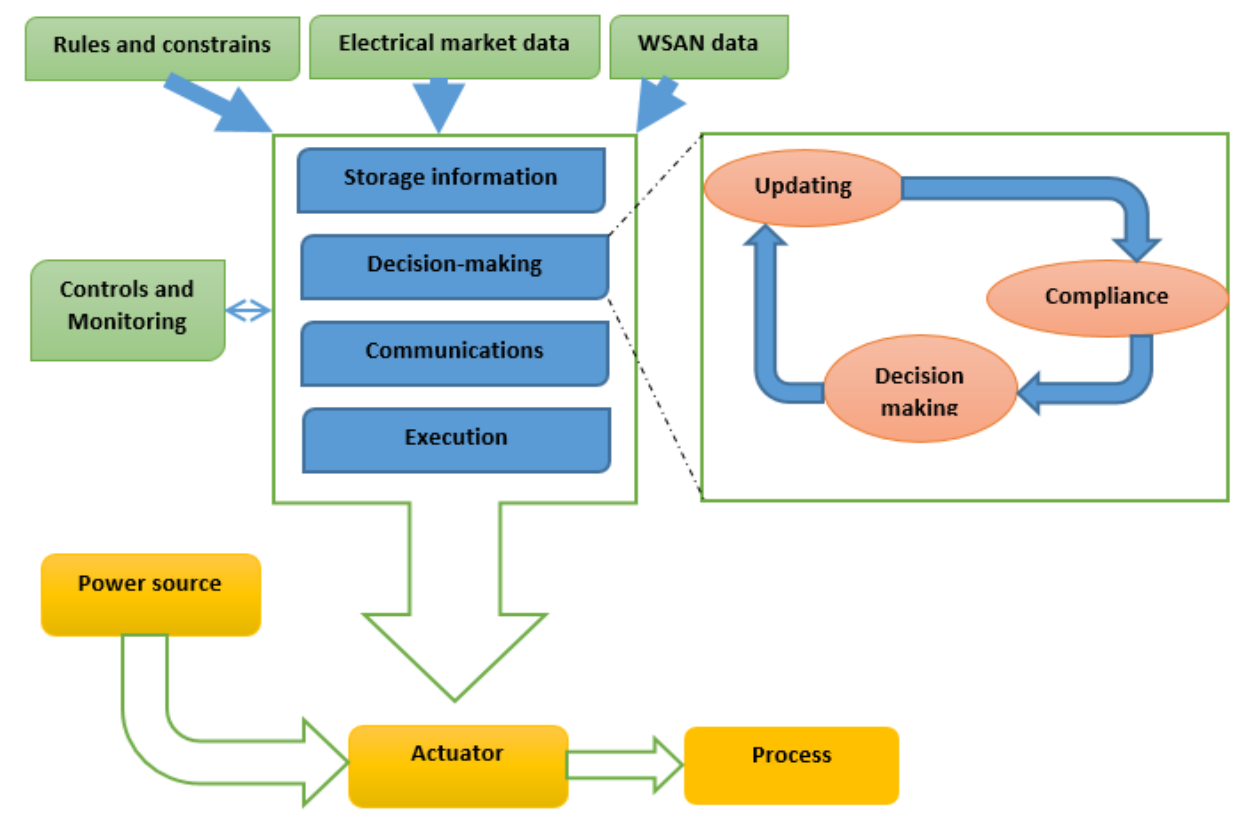

Figure 2. Logical architecture of the system 
For further increasing the life quality, smart houses and enhanced living environments are designed. In this regard, more supportive platforms are developed for smart houses. Some of these platforms use cloud systems for remote supervision, control and data storage. There is a significant issue for both industry and academia, represented by the way of reducing and estimating energy consumption for smart houses. Accordingly, this paper proposes a modular platform which utilizes the cloud services power to collect, aggregate and store all data collected from the smart environment [10].

Among the key motives for using smart plugs is to reduce energy loss while the electrical machines are operating. This is where the occupancy detection feature exists. A great quantity of energy can be saved through utilizing a proper occupancy driven control along with a smart plug. Particularly, devices of high power consumption like heaters, televisions, air conditioners, copying machines, etc., which are operated only when there is a user, can be turned into more energy-efficient devices through the use of this feature [11].

Appliance Load Monitoring (ALM) has been under research extensively; however, Hybrid Appliance Load Monitoring System (HALMS) has appeared recently as a new field of research.

A context-based technique is evaluated to anticipate the production and consumption of electricity in buildings. This study focuses on a household with photovoltaic and energy storage system. It analyzes the efficiency of Markov chains, stride predictors and their combination into a hybrid predictor in modelling the development of producing and consuming electricity [12].

The effective employment of (IoTs) is utilized for monitoring home machines. Wireless sensor networks based on real time power management system are presented to control and monitor the power consumption of electrical machines at home. The power consumption of electrical machines was calculated using the current and voltage sensors. After that, the measured data were transmitted wirelessly through the use of Zigbee protocol to Ethernet shield for remote monitor and control through a secured internet web connection. Therefore, this system can be utilized to reduce the cost of electricity for consumers [13]. In spite of smart campus can be considered as a smart environment of teaching based on the IoT and its application some problems are still found in life. This is particularly in relation to monitoring the energy and resource which still in the classical daily life mode. Nowadays, the method of monitoring is real time base and efficient in the most aspects [14]. A WSN is designed and implemented based on ZigBee technology. It's composed of base station, ZigBee, end nodes with router ZigBee and host computer [15].

The integrity between the WSNs with IoT is used in this study to present sufficient way to visualize and control the power in electrical equipment's at home. The power utilization during the operation is displayed instantaneously. Any variation of power from the rated can be adapted and compensated manually.

\section{MATERIALS AND METHODS}

The wireless sensors arise in heavily scattered networks, providing better a monitoring position resolution compared to the other classical systems. The current study introduces an intelligent wireless network measurement system, which combined the ability of sensor network with a cloud system to develop efficient WSN. The distributed sensor nodes are used with ZigBee. The transmitted measurement information or data occur through a output ports. A highly precision cloud computing system is used with the sensor network to perform all necessary operation such as measuring data monitoring and control the data. Artificial intelligence techniques employed to improve the detection and identification of th processed data [16]. This section clarifies materials and methods used for monitoring, control and detecting specific compounds. To achieve the objectives of the proposed technique, a cloud linked WN sensors is developed. The development of the complete set up to is fabricated. The schematic diagram of this circuit is described in Figure 3. The block diagram of the base station is shown in Figure 4.

The proposed system consists of three parts:

1. Smartphone application(Blynk),

2. base station,

3. Sensing node.

These facilities used to create to control the electrical appliance remotely [17]. The basic units of WSNs are sensors. Sensors are devices designed with features of innovative sensation. The sensor nodes appear as autonomous systems miniaturized with a set of units [18]. AC voltage and current sensor with Hall effects with Arduino Uno microcontroller to calculate the real-time power consuming of connected electrical appliances. The sensor includes (5) basic units, as clarified in Figure 4. Sensor function layout as shown in Figure 5. 


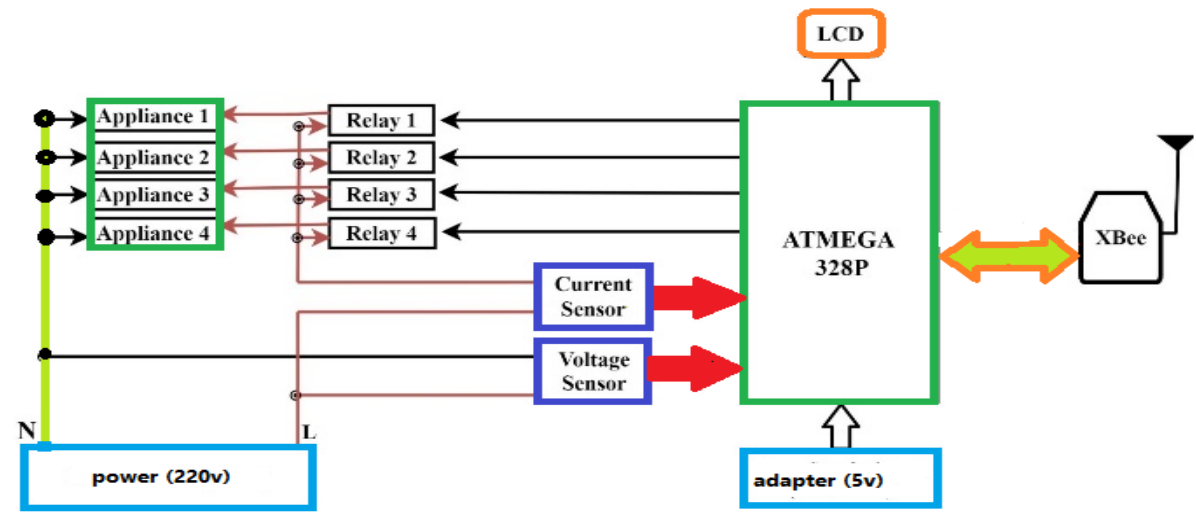

Figure 3. Sensing node block diagram

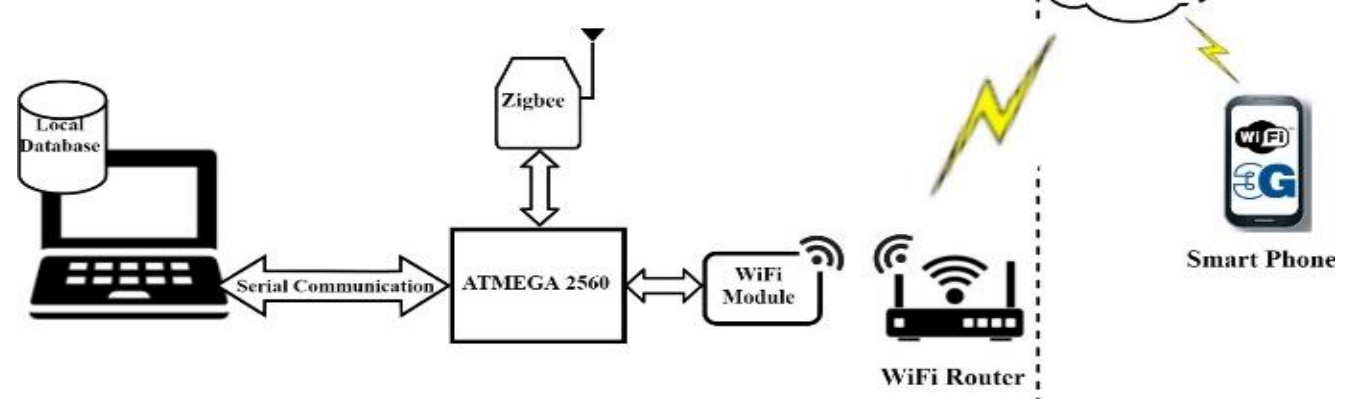

Figure 4. Base station block diagram

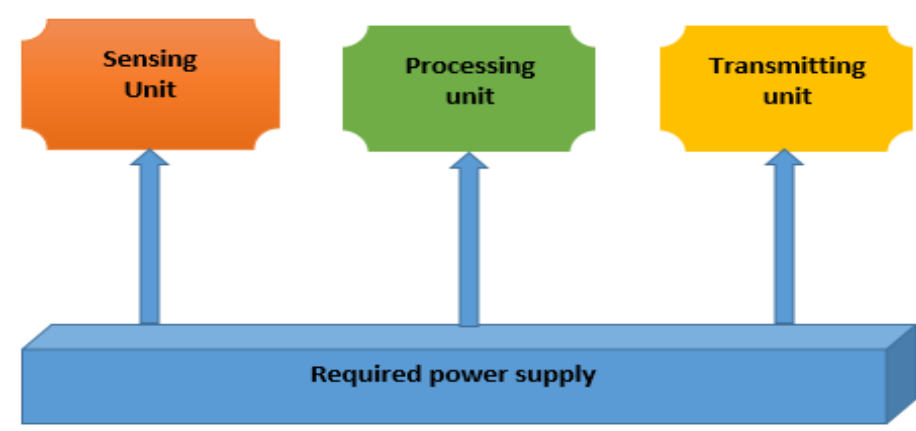

Figure 5. Sensor function layout

The voltage sensor used in this work is single-phase AC voltage sensor, which is made of ZMPT101B voltage transformer.

For sensing current, ACS712 is used for this purpose. For calculating power of a single-phase AC circuit, the output of volts and amperes must be multiplied by the power factor. The power is calculated at the microcontroller after receiving voltage outputs from corresponding current and voltage sensors as in (1).

$$
P=V_{r m s} I_{r m s} \cos \theta, \cos \theta=P F
$$


Where Vrms, Irms, PF is the supplied voltage, drawn current and power factor, respectively. Then, accumulated power consumption is calculated with run time of appliances in order to calculated $\mathrm{KWh}$ as in (2).

$$
\text { Power consumed }(K W h)=\frac{\text { power in Watt *Time per hour }}{1000}
$$

The measured readings are displayed using the liquid crystal display (LCD) and a relay is added to allow control of appliances either according to consumer requirements by sending commands wirelessly from a base station to a microcontroller; or when exceeding permitted consumption limits, it will automatically turn off the power. ZigBee module will be responsible for wirelessly sending all the measured readings in this part to the base station. The base station is designed to receive all transmitted measured readings from sensing node to continue monitoring in the real-time through graphical user interface (GUI) available at computer system and the mobile application window. Monitoring of the power help the user to reduce the power consumption, which would save cost. These measured readings are stored in database for further analysis. There are few delay variances in time over the platforms due to their different hardware selections or the functional behavior of GUI [19].

When the project application is started, the server authentication token with project code downloaded from iOS mobile app from App Store or any search engine. Figure 6 depicts the fabricated system with the integrated sensing circuit and ZigBee module.

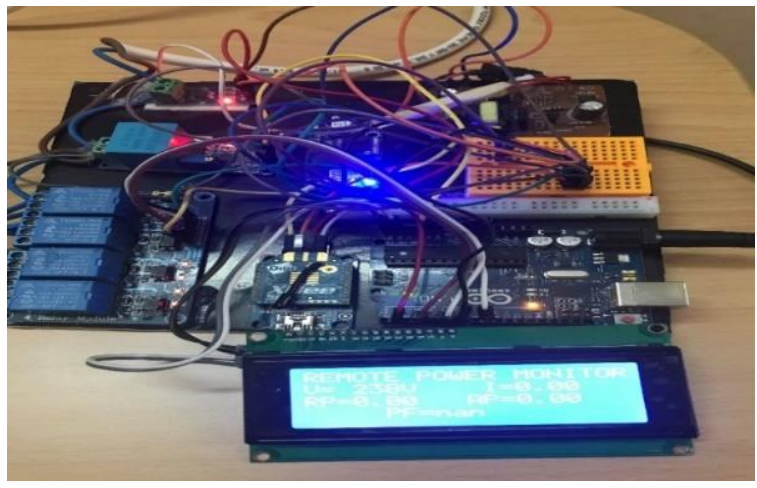

Figure 6. Fabricated smart power monitoring unit

\section{SYSTEM IMPLEMENTATION}

The power consumption parts are optimized based on the support of all software modules with WSN data updating mechanism to achieve the proposed objectives in the simulations and graphical used interface(GUI) capability to visualize the results. Finally, the practical implementation part presents numerical and graphical representations of each performance specification of the components and appliances monitoring and control [20-21]. By monitoring the power consumption of the devices, the data is collected by the ZigBee coordinator for the base station. Then, all these data are saved in the database at computer system to be processed and analyzed, as well as in the cloud database for remote access. Figure 7 displays the electrical parameters on GUI. Both communication and wireless networks can be integrated to increase the capacity and decrease the costs in the access networks [22-23].

The Blynk app works when the light bulb, television and laptop charger are connected to the sensing node, as shown in Figure 8.

In addition, the system depends on the average of drawn current that is identified in the program (13A). This means that the appliances can be turned on or off automatically. The relays work and the power is cut when the drawn current exceeds 13A, as shown in Figure 9. The measured readings are processed using visual studio programming. 


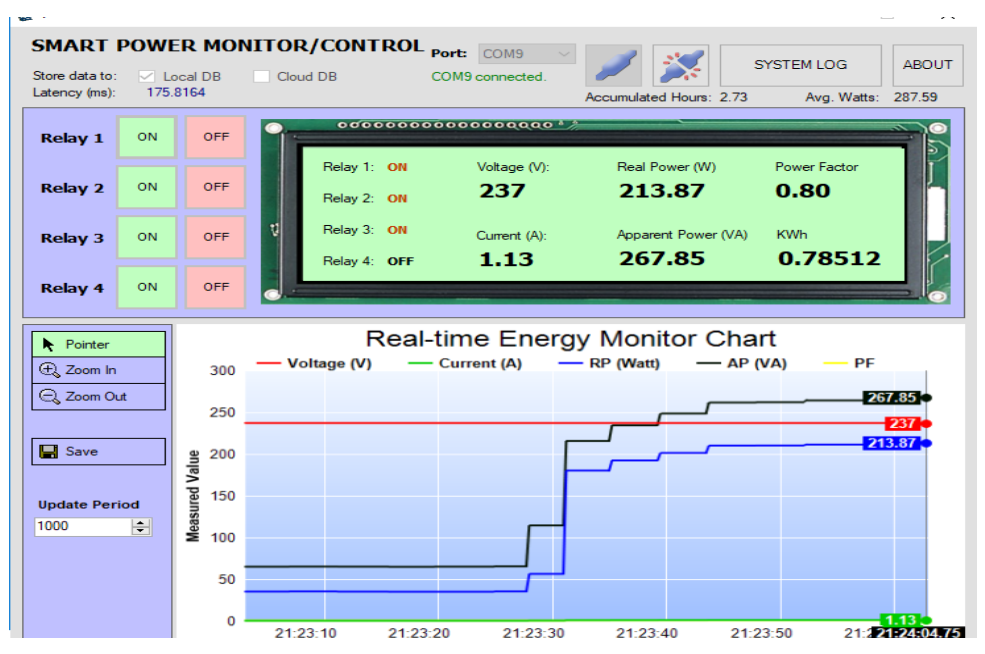

Figure 7. Screenshot of GUI

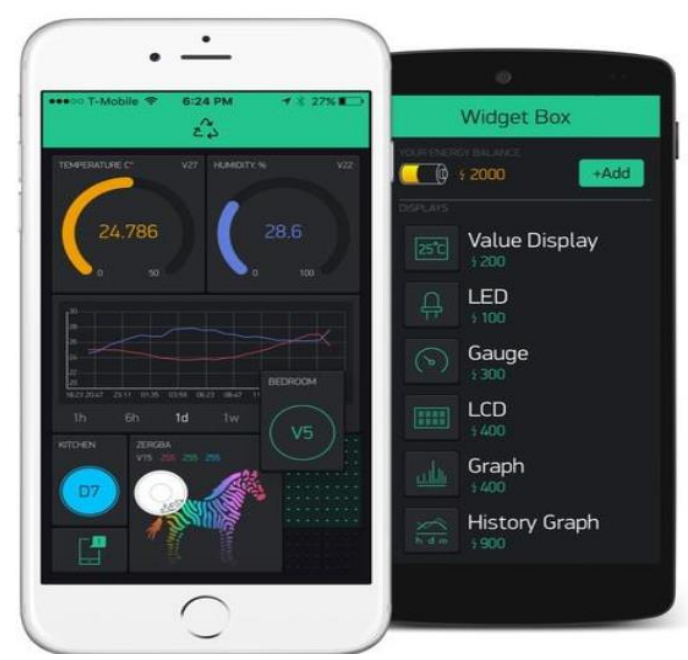

Figure 8. Blynk app overview

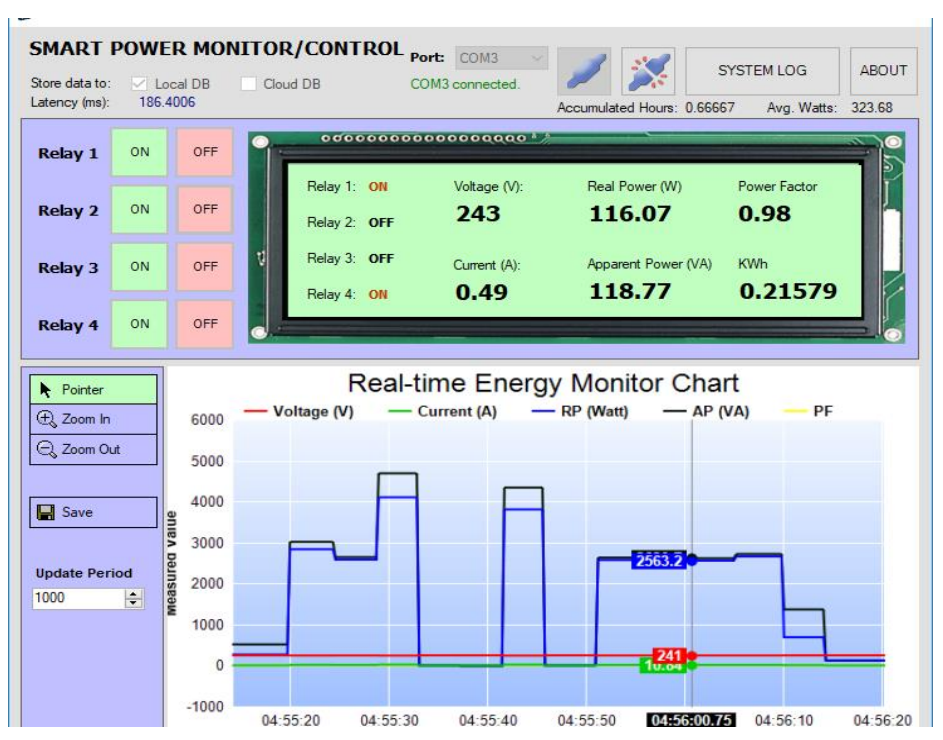

Figure 9. Automatically turn off power of appliances at (13 A) 


\section{RESULTS}

This section presents the results obtained from testing various household electrical appliances. The electrical parameters are obtained from the system versus practical results graph, as shown in Figure 10. Comparison between supplied voltage of system and practicality is shown in Figure 11. The Comparison between power consumption of system and practicality is shown in Figure 12. Power factor measurement for different home appliances is shown in Figure 13.

As shown in Figure 13, the power factor value varies for each appliance. When the appliance is a lamp, an iron, a water heater and a toaster, this means resistive type whose value is close to 1 . Either the remaining appliances are of an inductive type whose value is far from 1.

Figure 14 shows real power versus apparent power graph when PF value is 0.98 . This means that the type of load is almost resistant (current and voltage in-phase). In this case, the lost power will be very small, so the value of real power is approaching the apparent power.

Figure 15 shows real power versus apparent power graph when PF value is 0.5 . This means that the load type is inductive.

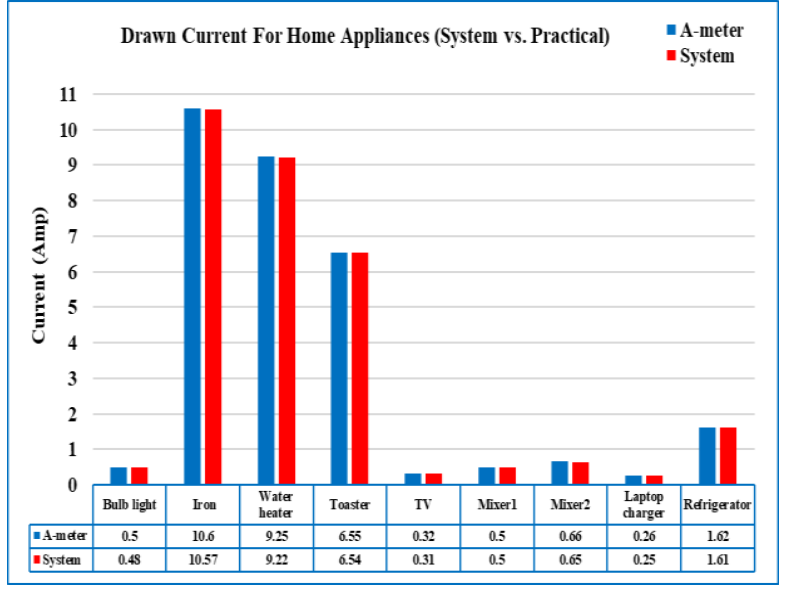

Figure 10. Comparison between drawn current of system and practical results

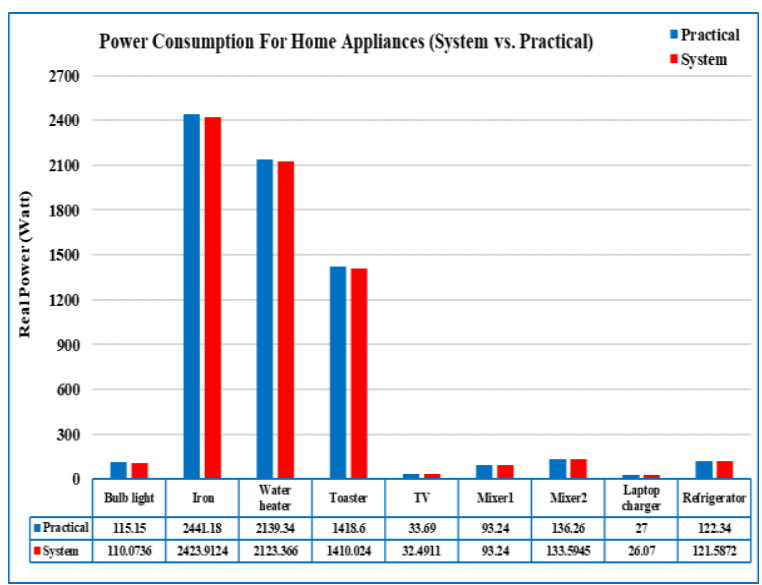

Figure 12. Comparison between power consumption of system and practicality

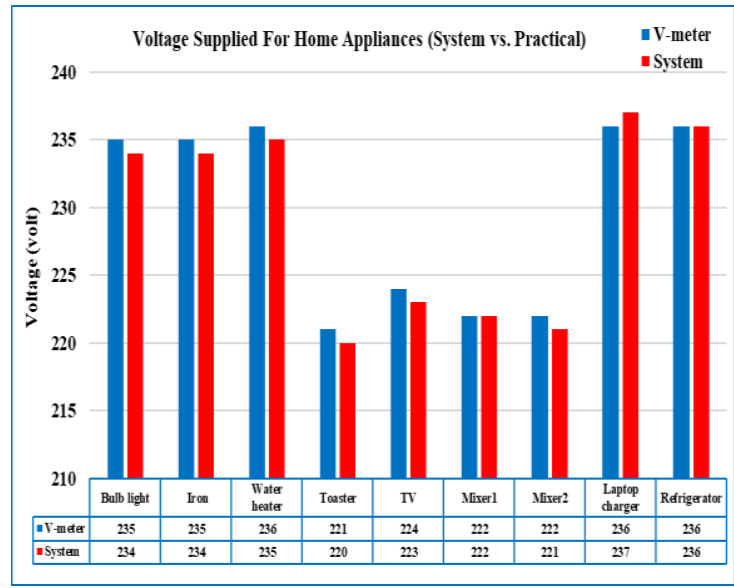

Figure 11. Comparison between supplied voltage of system and practicality

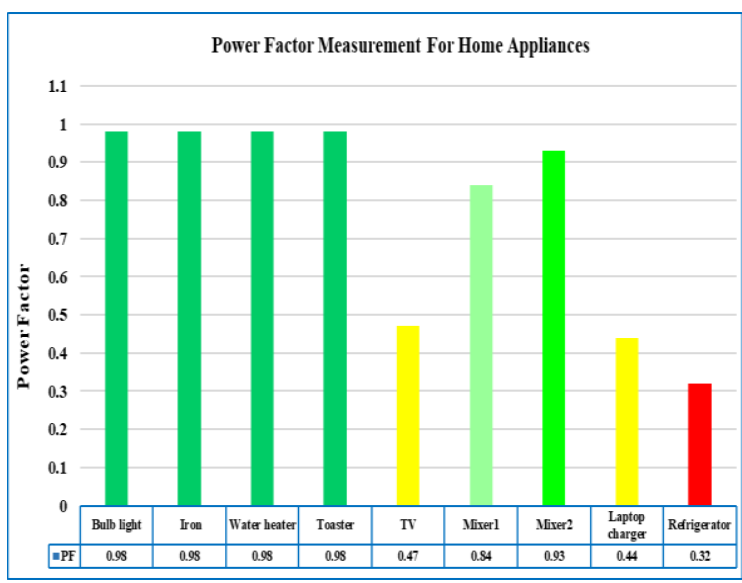

Figure 13. Power factor measurement for different home appliances 


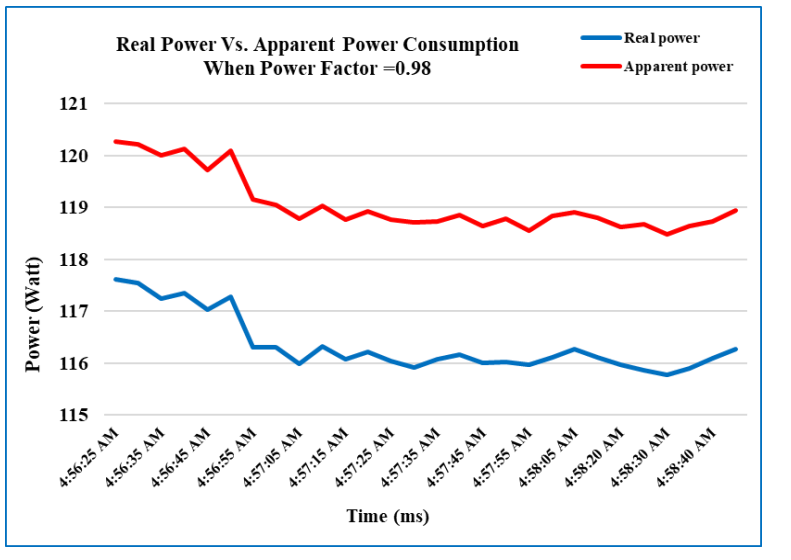

Figure 14. Real power vs. apparent power consumption $(\mathrm{PF}=0.98)$

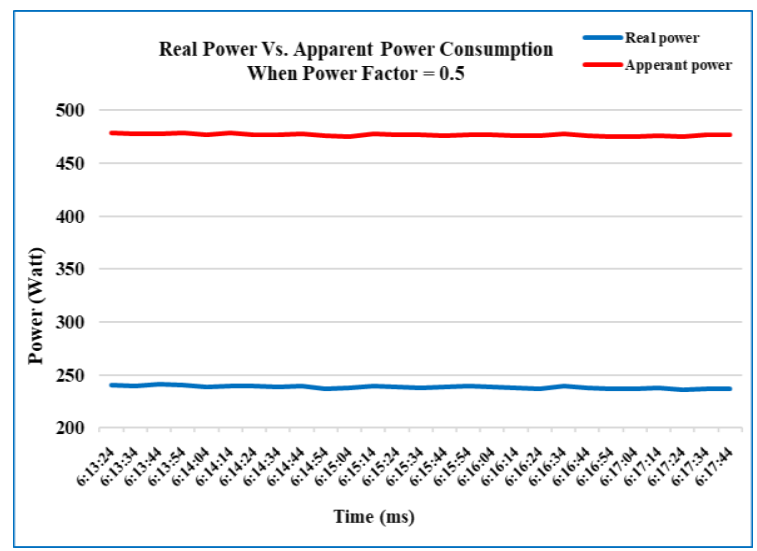

Figure 15. Real power vs apparent power consumption $(\mathrm{PF}=0.5)$

In addition, the sensing node is tested to check the $\mathrm{kWh}$ consumption at different run-times of the system. Figure 16 shows KWh consumption when runtime of system is 15 minutes. Energy consumption (KWh) for 2 hours in Figure 17.

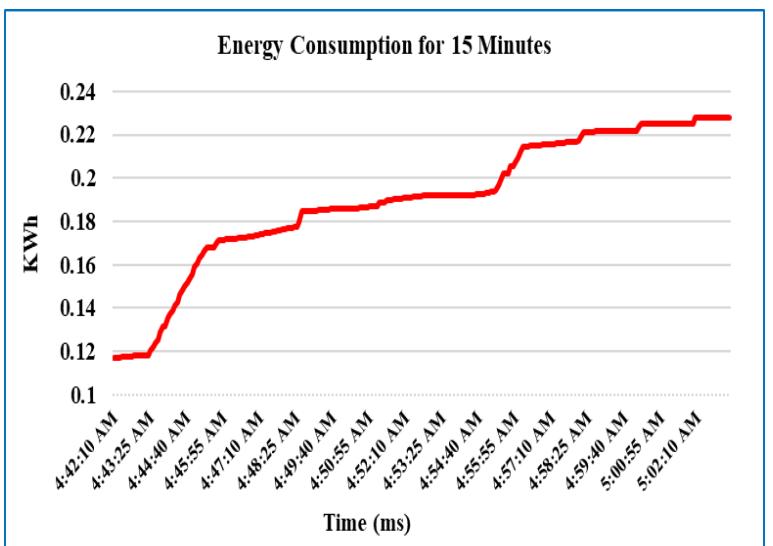

Figure 16. Energy consumption (KWh) for 15 Minutes

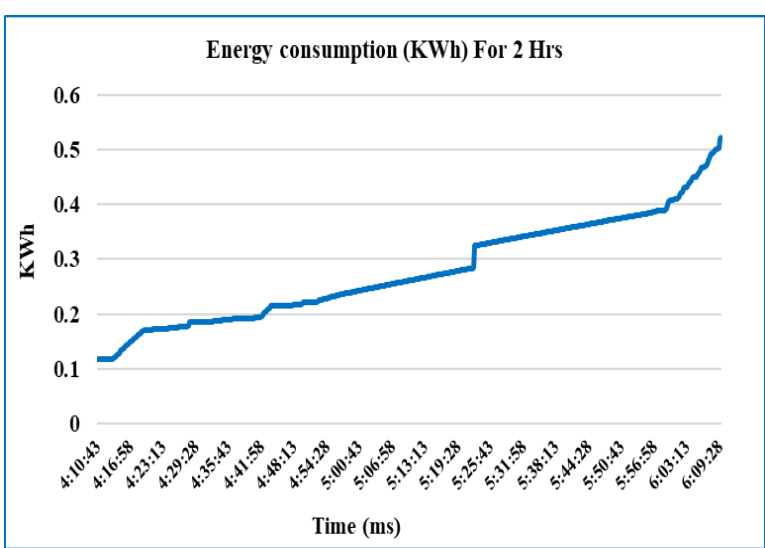

Figure 17. Energy consumption (KWh) for 2 hours

Figure 18 shows the voltage measurement for the specified period, where the voltage fluctuates to obtain a stable voltage due to instability of voltage that is provided for home. Figure 19 shows the drawn current measurement for the specified period.

The error ratio between the practical measurement of the appliance and the simulated measurement is less than $0.3 \%$ in voltage. The error ratio between the practical measurement of the appliance and the simulated measurement is less than $1.45 \%$ in current and less than $1.78 \%$ in the power consumption.

The base station is implemented in order to continue monitoring for the consumption amount of electrical parameters for all connected appliances at sensing unit and the control. The measured readings will be sent wirelessly using ZigBee that exists in the sensing unit. The base station will be simply represented by the Arduino MEGA, XBee S2C, NodeMCU, serial cable and PC[24-25]. In addition, Internet Residential Gateway is used to remote monitoring and control through smartphone app (Blynk app). Figure 20 shows the base station implementation. 


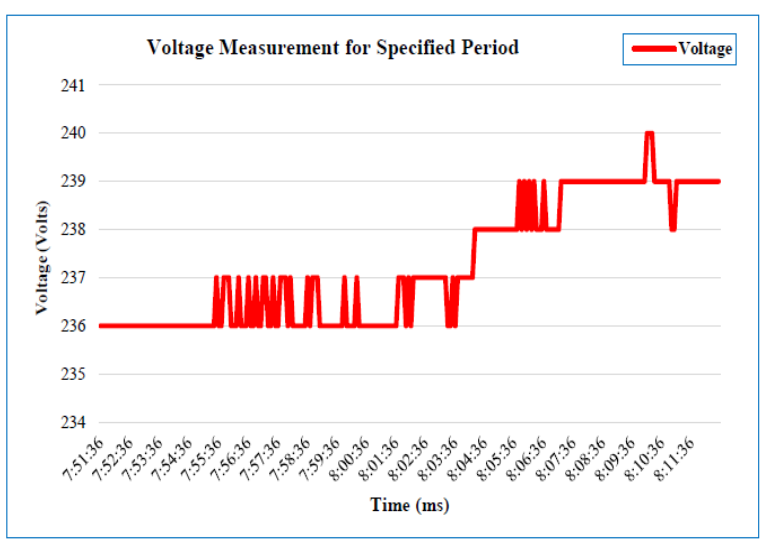

Figure 18. Voltage measurement during the operation

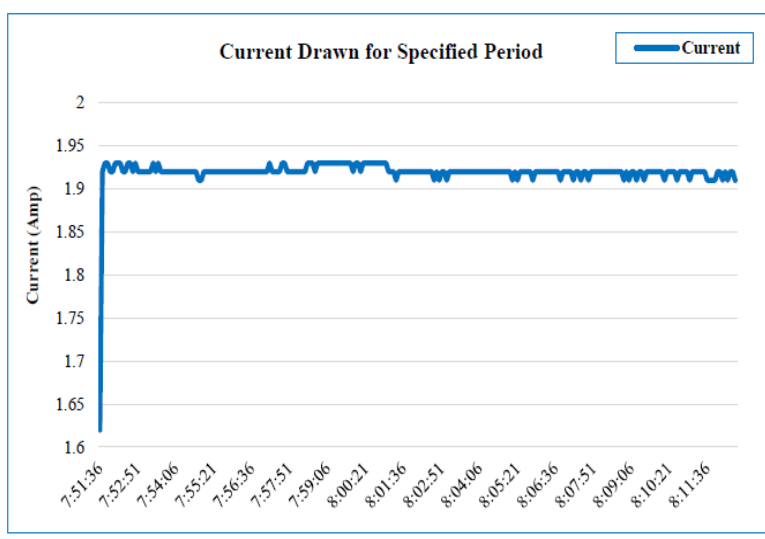

Figure 19. Current measurement during the operation

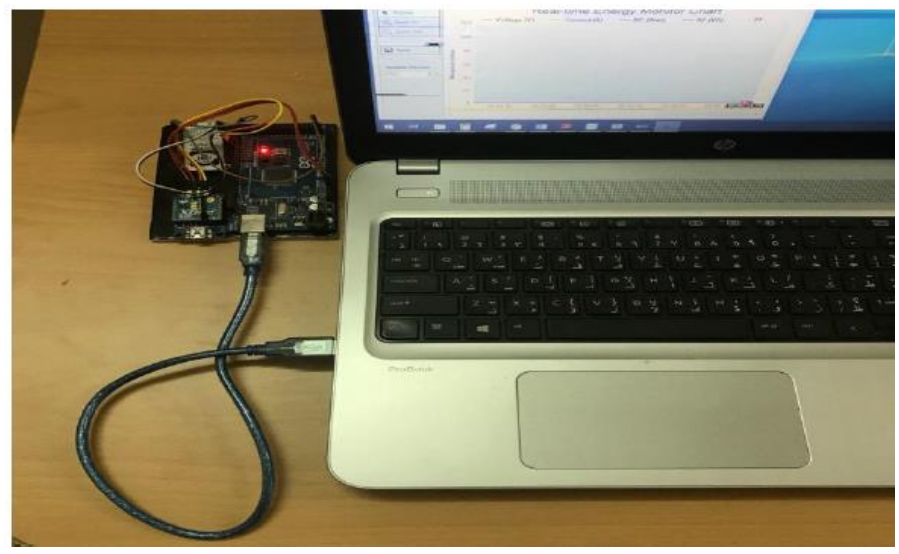

Figure 20. Screen shot of base station

\section{CONCLUSION}

Considered as optimization base of the new control and monitoring of power resources demand for the homes and smart cities at each moment.New improvement can be achieved through the global position system with IoT and WSN capabilities together in real time. This study has presented implementation of an intelligent monitoring and control of power system in efficient way either in automatic or in manual. Low cost implementation of the WSAN using Zugbee and the sensor environmental components for saving power. The power consumption directly proportional with operation time of the system.

\section{REFERENCES}

[1] Iman Mohammed Nayyef, Anas Ali Husein. "Design and Implementation of IOT Based Smart Power Monitoring and Managexment System Using WSNS". International Journal of Embedded Systems and Applications (IJESA), vol 8, no.4, 1-16, 2018.

[2] Nur Ashida Salim, Hasmaini Mohamad, Zuhaila Mat Yasin, Nur Fadilah Ab Aziz, Nur Azzammudin Rahmat," Graphical user interface based model for transmission line performance implementation in power system", Indonesian Journal of Electrical Engineering and Computer Science (IJEECS), vol 16, no. 1,pp. 92-100, 2019.

[3] Yasin Kabalci. "IEEE 802.15.4 Technologies for Smart Grids. Smart Grids and Their Communication Systems", pp 531-550, 2019.

[4] Khalaf S Gaeid,Nada N Tawfeeq, Mahdi J Marie" Computer Control of Teaching Enhancement by Communication Networked" Indonesian Journal of Electrical Engineering and Computer Science (IJEECS), vol. 18, no. 2, 2020, in press.

[5] Danielly B.Avancini, Joel J.P.C.Rodrigues, Simion G.B. Martins, Ricardo A.L.Rabêloc, Jalal Al-Muhtadide, Petar Solic. "Energy meters evolution in smart grids: A review". Journal of Cleaner Production. vol 217, pp. 702-715, 2019. 
[6] Mohamed Medhat Gaber Adel Aneiba Shadi Basurra Oliver Batty Ahmed M. Elmisery Yevgeniya Kovalchuk Muhammad Habib Ur Rehman. "Internet of Things and data mining: From applications to techniques and systems". Wires journal, vol. 9, no.3, 2019.

[7] Mohammad Asif Hossain, Rafidah Md Noor, Kok-Lim Alvin Yau, Ismail Ahmedy, Shaik Shabana A. "A Survey on Simultaneous Wireless Information and Power Transfer with Cooperative Relay and Future Challenges". IEEE Access ,vol. 7, pp19166-19198, 2019.

[8] S. G. Phuke \& K. N. Kasat. "A Review of Smart Power Monitoring and Controlling System in View of an Intelligent Building", International Journal of Innovative and Emerging Research in Engineering, vol. 2, no. 2, pp. 169-173, 2015.

[9] Jess Blanco, Andrés Garca and Javier de las Morenas. "Design and Implementation of a Wireless Sensor and Actuator Network to Support the Intelligent Control of Efficient Energy Usage”. Sensors 18, 1892, 2018.

[10] Dan PopaFlorin Pop, Cristina Serbanescu, Aniello Castiglione, "Deep learning model for home automation and energy reduction in a smart home environment platform". Neural Computing and Applications, vol 31, no. 5, pp. 1317-1337, 2019.

[11] Nagender Kumar Suryadevara, and Gyan Ranjan Biswal. "Smart Plugs: Paradigms and Applications in the Smart City-and-Smart Grid”. Energies, vol. 12, no.10, 1957, 2019.

[12] Arpad Gellerta, Adrian Floreaa, Ugo Fioreb, Francesco Palmieric, Paolo Zanetti. "A study on forecasting electricity production and consumption in smart cities and factories". International Journal of Information Management Available online 15 January 2019.

[13] P. R. Joshi \& M. S. khan, "IOT Based Smart Power Management System Using WSN", International Research Journal of Engineering and Technology (IRJET), vol. 04, no. 06, pp. 783-786, 2017.

[14] Wenbin Zheng; Zhe Yang; Lei Feng; Ping Fu; Jinlong Shi. "APP Design of Energy Monitoring in Smart Campus Based on Android System”. International Journal of Online Engineering., Vol. 15,no.5, pp. 18-27, 2019.

[15] Anas Ali Hussien, Ali Hameed Tawfeeq. "ZigBee-Based Wireless Sensor Network for Temperature Monitoring". International Journal of Computers \& Technology, vol 10, no 10, pp. 2062-2072, 2013.

[16] Patricia Arroyo, José Luis Herrero, José Ignacio Surez and Jess Lozano. "Wireless Sensor Network Combined with Cloud Computing for Air Quality Monitoring” Sensors,vol.19,no. 3, p. 691, 2019.

[17] https://iotdesignpro.com/projects/temperaturehumidity-monitoring-over-blynk-app-using-esp8266-and dht11

[18] Hamami Loubna and Nassereddine Bouchaib, "Integration of Irrigation System with Wireless Sensor Networks: Prototype and Conception of Intelligent Irrigation System". Proceedings of the World Congress on Engineering and Computer Science, vol I WCECS, San Francisco, USA, 2018.

[19] Daming Li, Lianbing Deng, Minchang Lee, Haoxiang Wang, "IoT data feature extraction and intrusion detection system for smart cities based on deep migration learning". International Journal of Information Management, Available online 10 May 2019, In Press.

[20] Somasekhar Reddy Kandukuri. "Spatio-Temporal Adaptive Sampling Techniques for Energy Conservation in Wireless Sensor Networks". Doctoral Thesis in Computer Networks \& Signal Processing. University of Reunion, 2017.

[21] Khalaf S. Gaeid,Ali Saghafinia, Ziad Hussein Salih, "Sliding Mode Control of Induction Motor with Vector Control in Field Weakening" Modern Applied Science journal, vol. 9, no. 2,pp, 286-299, 2015.

[22] Adnan Hussein Ali, Hayder Jasim Alhamdane, Begared Salih Hassen, "Adnan Hussein Ali, Hayder Jasim Alhamdane, Begared Salih Hassen", Indonesian Journal of Electrical Engineering and Computer Science (IJEECS), vol 15, no 2, pp. 870-878, 2019.

[23] José Alcaina, Ángel Cuenca, Julián Salt, Minghui Zheng, Masayoshi Tomizuka, ”Energy-Efficient Control for an Unmanned Ground Vehicle in a Wireless Sensor Network" Journal of Sensors, vol. 2019, pp. 1-16, Article ID 7085915.

[24] W. P. M. H. Heemels, M. C. F. Donkers, and A. R. Teel, "Periodic event-triggered control for linear systems," IEEE Transactions on Automatic Control, vol. 58, no. 4, pp. 847-861, 2013.

[25] X.-M. Zhang, Q.-L. Han, and X. Yu, "Survey on recent advances in networked control systems," IEEE Transactions on Industrial Informatics, vol. 12, no. 5, pp. 1740-1752, 2016. 